\title{
New spaces of the geographies of health and health care
}

\author{
Mark W. Rosenberg
}

Published online: 13 May 2009

(C) Springer Science+Business Media B.V. 2009

Health Geography has been differentiated from medical geography by its attention to broader definitions of health that go beyond the biomedical perspective of an absence of disease, the framing of health issues within critical-social-theoretical frameworks, the use of qualitative methodology and mixed methods, and an attention to the meaning of place (see Gatrell 2002). The papers in this special issue capture some or all of these characteristics and in addition, focus on topics, which have received little or no attention in medical or health geography.

The papers mainly had their genesis in sessions held at the Annual Meetings of the Association of American Geographers (AAG) in San Francisco, USA in 2007 and organized by the then chairperson of the International Geographical Union Commission on Health and the Environment, Mark Rosenberg, on its behalf. Rosenberg was looking for some of the new cohort of health geographers who are in the early stages of their careers and are leading the next wave of thinking in health geography to present recent research they have carried out.

The papers by Wilson and Ross, Skinner and Joseph, and Place and Hanlon expand health geography into areas at the intersections with public health (Wilson and Ross), the "Third Sector" (Skinner and

M. W. Rosenberg ( $₫)$

Department of Geography, Queen's University, Kingston,

ON K7L 3N6, Canada

e-mail: mark.rosenberg@queensu.ca
Joseph), and environmental-economy policy debate (Place and Hanlon). A critical focus on vulnerable populations (youth, people living with HIV/AIDS, immigrant women, the elderly population, Aboriginal Peoples) in increasingly complex settings is a theme in five of the papers. The changing macro political and economic conditions and the implications for our understanding of the delivery of health and social services is a theme that is even more key today than at the time the papers by Fleuret and Skinner and Joseph were written. These two papers provide important understandings for what is likely to occur in the coming years as publicly-funded health and social service delivery systems come under attack as government deficits increase. Lovell and Rosenberg and Crooks et al. speak to the complexity of linking community and vulnerable groups in the delivery of specialized services. What follows is a group of papers which are leading the way in opening up new spaces in the geographies of health and health care.

\section{References}

Gatrell, A. C. (2002). Geographies of health. Oxford: Blackwell. 